\title{
The natural anti-tubercular agents: In silico study of physicochemical, pharmacokinetic and toxicological properties
}

\author{
Mohammad Firoz Khan ${ }^{1}$, Md. Abdul Bari ${ }^{1}$, Md. Kamrul Islam ${ }^{1}$, Md. Shariful Islam ${ }^{1}$, Md. Shahidulla Kayser ${ }^{1}$, \\ Nusrat Nahar ${ }^{2}$, Md. Al Faruk ${ }^{3}$, Mohammad A. Rashid ${ }^{4 *}$ \\ ${ }^{1}$ Computational Chemistry and Bioinformatics Laboratory, Department of Pharmacy, State University of Bangladesh, Dhaka- 1205, Bangladesh. \\ ${ }^{2}$ Department of Microbiology, University of Dhaka, Dhaka- 1000, Bangladesh. \\ ${ }^{3}$ Department of Pharmacy, Daffodil International University, Dhaka, Bangladesh. \\ ${ }^{4}$ Department of Pharmaceutical Chemistry, University of Dhaka, Dhaka- 1000, Bangladesh.
}

\section{ARTICLE INFO}

Article history:

Received on: 26/01/2017

Accepted on: 22/03/2017

Available online: 30/05/2017

Key words:

Anti-tubercular agents;

Virtual screening;

Physicochemical properties;

Pharmacokinetics;

Toxicological properties.

\begin{abstract}
The purpose of the present study is to explore the physicochemical, pharmacokinetic and toxicological properties and to correlate the calculated physicochemical properties with the absorption and distribution profile of seven natural anti-tubercular agents such as 6a,7-dehydro-N-formylnornantenine (DNF), Aristololactam (AL), Isoambreinolide (IA), Andrographolide (AGD), 8,8'-Biplumbagin (BPG), Plumericin (PC) and Tiliacorine (TC). The physicochemical properties such as intrinsic solubility (solubility of unionized form) in water $(\operatorname{logS}$ ), partition coefficient $(\log \mathrm{P}), \mathrm{H}$ bond donor and acceptor count were calculated using MarvinSketch software. The pharmacokinetic and toxicological properties were calculated using online server PreADMET. The calculated aqueous solubility demonstrated that all the seven compounds possess limited solubility which ranged from very slightly soluble to practically insoluble. The calculation of partition coefficient suggested that all the compounds are lipophilic in nature and have higher affinity to reside in $n$-octanol than in water. The human intestinal absorption (HIA), Caco-2 cell penetrability, plasma protein binding (PPB) and $\mathrm{C}_{\text {brain }} / \mathrm{C}_{\text {blood }}$ of the seven compounds were ranged from $94.89 \%-100.00 \%, 20.18-54.75 \mathrm{~nm} / \mathrm{s}, 73.52 \%-100.00 \%$ and $0.353-2.331$, respectively. The computed metabolism demonstrated that DNF, AL, IA, PC and TC are substrate for cytochrome P450 3A4. However, all the compounds displayed inhibitory characteristics against cytochrome P450 3A4. The virtual screening also demonstrated that AL, PG and BPG are $2 \mathrm{C} 19$ inhibitors and all the natural agents except DNF are 2C9 inhibitors. In phase II reaction, IA, PG and DNF, AL, PG, BPG are the substrates for UDP-glucuronosyltransferase (UGT) and sulfotransferase (SULT), respectively. In the in silico mutagenicity and carcinogenicity investigations, all the compounds except TC exhibited mutagenicity. Among all the natural anti-tubercular agents only DNF and TC demonstrated carcinogenicity in both mouse and rat models. The AL and PG were carcinogenic only in mouse but in rat model they were noncarcinogenic. On the other hand, IA, BPG and PC were noncarcinogenic in both mouse and rat model. In addition, the risk of inhibition of human ether-a-go-go-related (hERG) gene was varied from low to medium risk. Our computed properties may be assistance for the development of promising candidates to combat M. tuberculosis with better pharmacokinetic and toxicological profile.
\end{abstract}

\section{INTRODUCTION}

Mycobacterium tuberculosis is a pathogenic bacterium that causes infectious disease called tuberculosis. This disease is

* Corresponding Author

Email: rashidma@du.ac.bd spreading all over the world. Each year 8.8 million and 1.6 million new infections and deaths, respectively are taken place due to $M$. tuberculosis (Luckner et al., 2010). The emergence of resistant strain of $M$. tuberculosis against isoniazid and rifampicin is contributing to the spread and worsening the situation by extending the therapy from 6 months to nearly 2 years and thereby increasing 
the cost for therapy to about 20 times (Luckner et al., 2010). Multidrug resistant strains of $M$. tuberculosis demands new drugs to restrain the spreading control of tuberculosis. The natural system always serve as a repository and generally mankind always looks into actinomycetes (Mahajan et al., 2011; Adegboye and Babalola, 2013; Patel et al., 2014), fungi (Smith and Ryan 2009; Aly et al., 2011), cyanobactria (Singh et al., 2011) and plants (Abdallah, 2011; Katiyar et al., 2012) for the new drug candidates. Numerous drugs and chemical agents have already been identified and the identification process is still on ongoing.

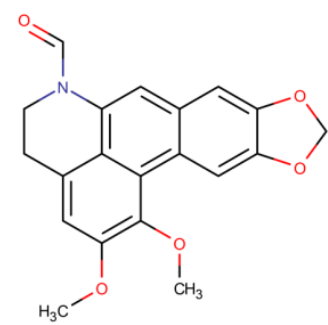

$1 \mathrm{~A}$

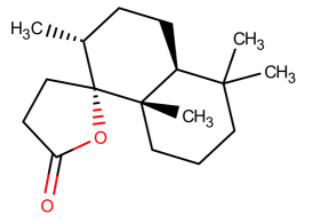

$1 \mathrm{C}$
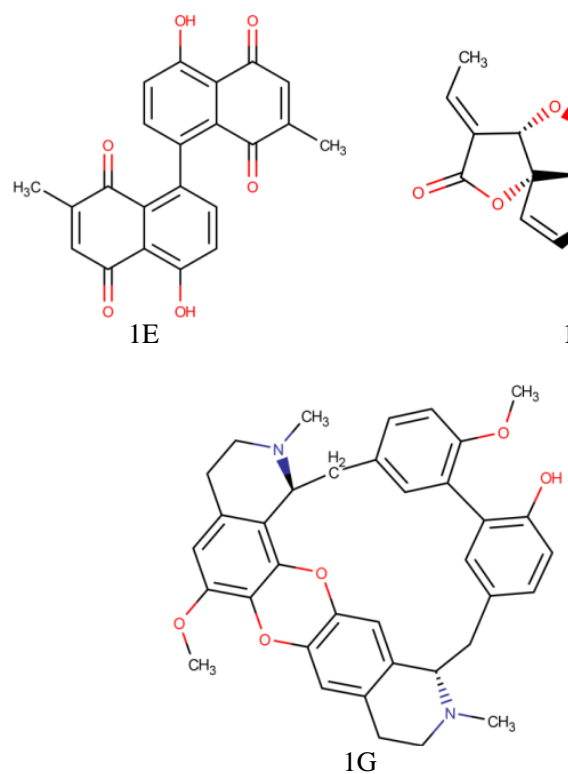

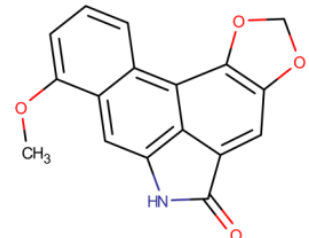

1B

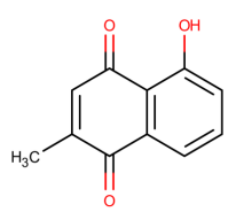

$1 \mathrm{D}$

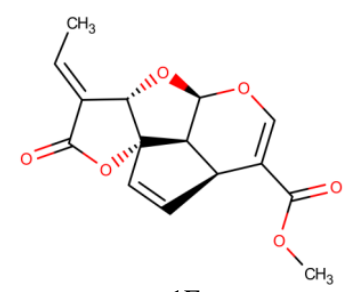

$1 \mathrm{~F}$ are reported to be active against $M$. tuberculosis (Pandit et al., 2015). The 6a,7-Dehydro-N-formylnornantenine (DNF), Aristololactam (AL), Isoambreinolide (IA), Andrographolide (AGD), 8,8'-Biplumbagin (BPG), Plumericin (PC) and Tiliacorine (TC) are the natural compounds reported to be effective against tuberculosis (TB) (Serkan et al., 2012; Sureram et al., 2012; Tiwari et al., 2013; Kumar et al., 2013; Uc-Cachon et al., 2014; Prabu et al., 2015). However, literature survey revealed that no report on the physicochemical, pharmacokinetic and toxicological properties of these compounds has been reported. In this study, we computationally investigated (a) physicochemical properties such as intrinsic solubility (solubility of unionized form) in water $(\log \mathrm{S})$, partition coefficient $(\log \mathrm{P}), \mathrm{H}$ bond donor and acceptor count, (b) pharmacokinetic properties like human intestinal absorption (HIA), cellular permeability using Caco-2 cell model, skin permeability $\left(\mathrm{P}_{\text {Skin }}\right)$, plasma protein binding (PPB), penetration of the blood brain barrier (BBB) and (c) toxicological properties including mutagenicity, carcinogenicity and risk of inhibition of human ether-a-go-go-related (hERG) gene. The purpose of this study was to explore the physicochemical, pharmacokinetic and toxicological properties and to correlate the calculated physicochemical properties with the absorption and distribution profile of DNF, AL, IA, AGD, BPG, PC and TC (Figure 1). These computed properties may be of assistance for the development of promising candidates to combat $M$. tuberculosis with better pharmacokinetic and toxicological profile.

\section{METHODOLOGY}

\section{Physicochemical properties}

The intrinsic solubility (solubility of unionized form) in water $(\operatorname{logS})$, partition coefficient $(\log \mathrm{P}), \mathrm{H}$ bond donor and acceptor count of 6a,7-Dehydro-N-formylnornantenine (DNF), Aristololactam (AL), Isoambreinolide (IA), Andrographolide (AGD), 8,8'-Biplumbagin (BPG), Plumericin (PC) and Tiliacorine (TC) were calculated using MarvinSketch 15.06.29 (ChemAxon (http://www.chemaxon.com)). The calculation of partition coefficient was conducted by applying both consensus and ChemAxon methods as implemented in MarvinSketch 15.06.29.

\section{Pharmacokinetic and toxicological properties}

The pharmacokinetic and toxicological properties were calculated using online server PreADMET (https://preadmet.bmdrc.kr/). This server enables to calculate pharmacokinetic and toxicological properties of chemical agents (Cunha et al., 2015). The pharmacokinetic properties such as human intestinal absorption (HIA), in vitro cellular penetrability using Caco-2 cell model, skin permeability $\left(\mathrm{P}_{\text {Skin }}\right)$, plasma protein binding (PPB) and penetration of the blood-brain barrier (BBB), interaction with P-glycoprotein (Pgp) and metabolism (both phase I and phase II) were calculated and predicted. However, virtual screenings were also performed to evaluate toxicological properties including mutagenicity, carcinogenicity and risk of inhibition of human ether-a-go-go-related (hERG) gene. 
Table 1: physicochemical property of natural anti-tubercular agents.

\begin{tabular}{|c|c|c|c|c|c|c|c|c|}
\hline \multirow[t]{2}{*}{ Compound Name } & \multirow{2}{*}{$\begin{array}{l}\text { Molecular } \\
\text { formula }\end{array}$} & \multirow{2}{*}{$\begin{array}{l}\text { Molecular } \\
\text { weight }\end{array}$} & \multicolumn{2}{|c|}{$\begin{array}{c}\text { Intrinsic aqueous } \\
\text { solubility }\end{array}$} & \multicolumn{2}{|c|}{$\begin{array}{c}\text { Partition } \\
\text { coefficient }(\log \mathrm{P})\end{array}$} & \multirow{2}{*}{$\begin{array}{c}\mathrm{H} \text { bond } \\
\text { donor }\end{array}$} & \multirow{2}{*}{$\begin{array}{r}\mathrm{H} \text { bond } \\
\text { acceptor }\end{array}$} \\
\hline & & & $\operatorname{logS}$ & $\mathrm{mg} / \mathrm{mL}$ & Consensus & ChemAxon & & \\
\hline 6a,7-Dehydro-N-formylnornantenine (DNF) & $\mathrm{C}_{20} \mathrm{H}_{17} \mathrm{NO}_{5}$ & 351.1 & -5.89 & 0.0005 & 2.35 & 2.21 & 0 & 5 \\
\hline Aristololactam (AL) & $\mathrm{C}_{17} \mathrm{H}_{11} \mathrm{NO}_{4}$ & 293.1 & -6.01 & 0.0003 & 2.54 & 2.49 & 1 & 4 \\
\hline Isoambreinolide (IA) & $\mathrm{C}_{17} \mathrm{H}_{28} \mathrm{O}_{2}$ & 264.2 & -4.5 & 0.0084 & 4.28 & 4.02 & 0 & 1 \\
\hline Plumbagin (PG) & $\mathrm{C}_{11} \mathrm{H}_{8} \mathrm{O}_{3}$ & 188.0 & -2.83 & 0.2781 & 2.24 & 1.69 & 1 & 3 \\
\hline 8,8'-Biplumbagin (BPG) & $\mathrm{C}_{22} \mathrm{H}_{14} \mathrm{O}_{6}$ & 374.1 & -6.55 & 0.0001 & 4.15 & 3.01 & 2 & 6 \\
\hline Plumericin (PC) & $\mathrm{C}_{15} \mathrm{H}_{14} \mathrm{O}_{6}$ & 290.1 & -3.25 & 0.1631 & 1.53 & 1.85 & 0 & 4 \\
\hline Tiliacorine (TC) & $\mathrm{C}_{36} \mathrm{H}_{36} \mathrm{~N}_{2} \mathrm{O}_{5}$ & 576.3 & -6.29 & 0.0003 & 6.16 & 5.64 & 1 & 5 \\
\hline
\end{tabular}

\section{RESULTS AND DISCUSSION}

\section{Physicochemical properties}

The intrinsic aqueous solubility ( $\log S)$, partition coefficient $(\log \mathrm{P}), \mathrm{H}$ bond donor and acceptor count of the investigated natural anti-tubercular agents are presented in Table 1. The table suggests that all the compounds possess limited aqueous solubility which ranged from very slightly soluble to practically insoluble (Sinko, 2010). This result is also supported by the calculation of partition coefficient which indicates that all the tested compounds are lipophilic in nature and have higher affinity to reside in $n$-octanol than in water i.e. all the compounds will pass the plasma membrane easily.

\section{Pharmacokinetic study}

The pharmacokinetic studies such as absorption, distribution and metabolism of DNF, AL, IA, AGD, BPG, PC and TC were performed using online server PreADMET (https://preadmet.bmdrc.kr/). The calculated absorption, distribution and metabolism parameters are presented in Table 2, Table 3 and Table 4, respectively.

The calculated human intestinal absorption (HIA) (Table 2) was ranged from $94.89 \%$ to $100.00 \%$ which suggest that all the tested compounds are well absorbed through the intestinal cell (Yee, 1997).

Table 2: Absorption characteristics of natural anti-tubercular agents.

\begin{tabular}{lccc}
\hline \multirow{2}{*}{\multicolumn{1}{c}{ Compound Name }} & \multicolumn{3}{c}{ Absorption characteristics } \\
\cline { 2 - 4 } & HIA $(\%)$ & $\mathbf{P}_{\text {Caco-2 }}(\mathbf{n m} / \mathbf{s})$ & $\mathbf{P}_{\text {skin }}$ \\
\hline 6a,7-Dehydro-N- & 97.37 & 42.46 & -4.41 \\
formylnornantenine (DNF) & 96.55 & 21.12 & -4.37 \\
Aristololactam (AL) & 100.00 & 53.66 & -1.58 \\
Isoambreinolide (IA) & 95.25 & 20.18 & -3.06 \\
Plumbagin (PG) & 94.89 & 20.58 & -3.27 \\
8,8'-Biplumbagin (BPG) & 96.05 & 23.15 & -4.29 \\
Plumericin (PC) & 97.49 & 54.75 & -3.57 \\
Tiliacorine (TC) & & & \\
\hline
\end{tabular}

In addition, all the compounds exhibited high permeability (Yazdanian et al., 1998) as absorption values through Caco-2 cell $\left(\mathrm{P}_{\text {Caco-2}}\right)$ was within 20.18 - $54.75 \mathrm{~nm} / \mathrm{s}$. The skin permeability $\left(\mathrm{P}_{\text {Skin }}\right)$ is a vital parameter for the assessment of drugs and chemical that might require transdermal administration. All the compounds were found to be impermeable through skin since the calculated $P_{\text {Skin }}$ value was negative.

The distribution properties were assessed by evaluating the brain to blood partition coefficient $\left(\mathrm{C}_{\text {brain }} / \mathrm{C}_{\text {blood }}\right)$, plasma protein binding (PPB) and interaction with the P-glycoprotein (Pgp). The calculated values of PPB were $73.52 \%$ to $100.00 \%$ (Table 3). Generally compounds with more than $90 \%$ of PPB are classified as strongly bound chemicals whereas less than $90 \%$ are weakly bound chemicals (https://preadmet.bmdrc.kr/admeprediction/). Therefore, among all the agents IA, PG and BPG bound strongly with plasma protein whereas DNF, AL, PC and TC are weakly bound chemicals. The $\mathrm{C}_{\text {brain }} / \mathrm{C}_{\text {blood }}$ values were 0.353 to 2.331. Based on $\mathrm{C}_{\text {brain }} / \mathrm{C}_{\text {blood }}$ ratio all chemicals fall under three categories namely high absorption to $\mathrm{CNS}\left(\mathrm{C}_{\text {brain }} / \mathrm{C}_{\text {blood }}\right.$ value more than 2.0), middle absorption to CNS $\left(\mathrm{C}_{\text {brain }} / \mathrm{C}_{\text {blood }}\right.$ value within 2.0 $0.1)$ and low absorption to $\mathrm{CNS}\left(\mathrm{C}_{\text {brain }} / \mathrm{C}_{\text {blood }}\right.$ value less than 0.1$)$ (Xiao-lei et al., 2005). The ratio of $\mathrm{C}_{\text {brain }} / \mathrm{C}_{\text {blood }}$ suggests middle to high absorption of these agents to CNS indicating moderate to higher ability to cross blood brain barrier (BBB).

Table 3: Distribution characteristics of natural anti-tubercular agents. Distribution characteristics

$\begin{array}{lllll}\text { Compound Name } & \text { Non } & & \text { No } \\ & 73.52 & 1.277 & \text { Non } & \text { No } \\ \text { 7-Dehydro-N- } & 80.24 & 1.368 & \text { Non } & \text { No } \\ \text { mylnornantenine (DNF) } & 97.49 & 2.331 & \text { Inhibitor } & \text { No } \\ \text { stololactam (AL) } & 100.00 & 0.851 & \text { Non } & \text { Nonstrate } \\ \text { mbagin (PG) } & 98.35 & 1.036 & \text { Inhibitor } & \text { Substrate } \\ \text {-Biplumbagin (BPG) } & 76.21 & 0.353 & \text { Non } & \text { No } \\ \text { mericin (PC) } & 79.91 & 0.789 & \text { Inhibitor } & \text { Substrate } \\ \text { acorine (TC) } & & & & \end{array}$

P-glycoprotein (Pgp), produced from the multi drug resistance (MDR) gene and an ATP dependent efflux transporter that affects the absorption, distribution and excretion of clinically important drugs (Schinkel, 1999). The Pgp over-expression may lead MDR which is the main cause of failure of cancer chemotherapy and reduced efficacy of antibiotics (Kim et al., 1998; Cabrera et al., 2006).

The prediction of Pgp substrates aids early detection and elimination of chemical agents of low effectiveness or high potential of MDR (Wang et al., 2005; de Cerqueira et al., 2006). Identification of drugs that are Pgp substrates is essential for drug discovery, but it is primarily done through laborious in vitro and in vivo investigations (Joung et al., 2012). 
Table 4: Metabolic (Phase I and Phase II) characteristics of natural anti-tubercular agents.

\begin{tabular}{|c|c|c|c|c|c|c|c|c|}
\hline \multirow[b]{3}{*}{ Compound Name } & \multicolumn{8}{|c|}{ Metabolism } \\
\hline & \multicolumn{6}{|c|}{ Phase I } & \multicolumn{2}{|c|}{ Phase II } \\
\hline & 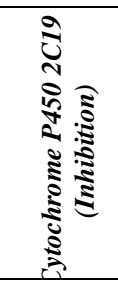 & 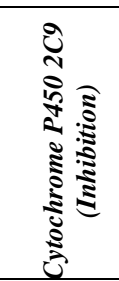 & 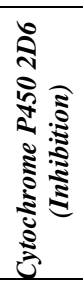 & 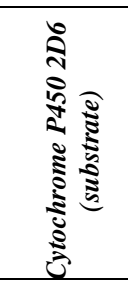 & 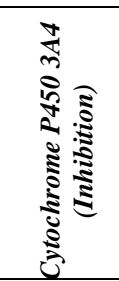 & 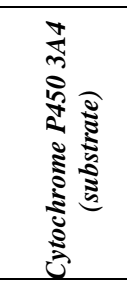 & 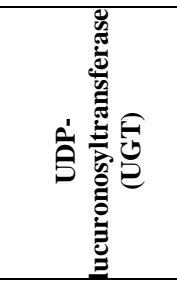 & 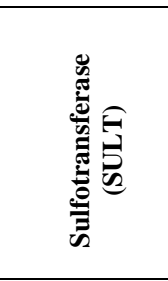 \\
\hline $\begin{array}{l}\text { 6a,7-Dehydro-N- } \\
\text { formylnornantenine (DNF) }\end{array}$ & Non & Non & Non & Non & Inhibitor & Substrate & Non-substrate & Substrate \\
\hline Aristololactam (AL) & Inhibitor & Inhibitor & Non & Non & Inhibitor & Substrate & Non-substrate & Substrate \\
\hline Isoambreinolide (IA) & Non & Inhibitor & Non & Non & Inhibitor & Substrate & Substrate & Non-substrate \\
\hline Plumbagin (PG) & Inhibitor & Inhibitor & Non & Non & Inhibitor & Non & Substrate & Substrate \\
\hline 8,8'-Biplumbagin (BPG) & Inhibitor & Inhibitor & Non & Non & Inhibitor & Non & Non-substrate & Substrate \\
\hline Plumericin (PC) & Non & Inhibitor & Non & Non & Inhibitor & Substrate & Substrate & Non-substrate \\
\hline Tiliacorine (TC) & Non & Inhibitor & Non & Substrate & Inhibitor & Substrate & Non-substrate & Non-substrate \\
\hline
\end{tabular}

Table 5: Toxicological properties of natural anti-tubercular agents.

\begin{tabular}{|c|c|c|c|c|}
\hline \multirow{2}{*}{ Compound Name } & \multirow{2}{*}{ Mutagenicity (Ames test) } & \multicolumn{2}{|c|}{ Carcinogenicity } & \multirow{2}{*}{ hERG inhibition } \\
\hline & & Mouse & Rat & \\
\hline 6a,7-Dehydro-N-formylnornantenine (DNF) & Mutagen & Negative & Negative & Medium risk \\
\hline Aristololactam (AL) & Mutagen & Negative & Positive & Medium risk \\
\hline Isoambreinolide (IA) & Mutagen & Positive & Positive & Low risk \\
\hline Plumbagin (PG) & Mutagen & Negative & Positive & Low risk \\
\hline 8,8'-Biplumbagin (BPG) & Mutagen & Positive & Positive & Medium risk \\
\hline Plumericin (PC) & Mutagen & Positive & Positive & Low risk \\
\hline Tiliacorine (TC) & Non-Mutagen & Negative & Negative & Medium risk \\
\hline
\end{tabular}

Computational classification model can be used to screen molecules and predict the likeliness to be substrate for Pgp (Joung et al., 2012). The in silico screening revealed that BPG and TC is a dual inhibitors and substrates for Pgp. on the other hand, IA will act as an inhibitor of Pgp. This proves that IA is likely to be active in cells expressing high levels of Pgp.

The computed metabolism (Table 4) demonstrated that DNF, AL, IA, PC and TC are substrate for cytochrome P450 3A4. However, all the compounds displayed inhibitor characteristics against cytochrome P450 3A4. This is because due to complex modulatory interactions with the cytochrome P450 3A4 which make them to function as combinations of substrate and inhibitor (Zhou, 2008). The virtual screening also demonstrated that AL, PG and BPG are 2C19 and all the natural agents except DNF are 2C9 inhibitors. In phase II reaction, the substrates for UDPglucuronosyltransferase (UGT) are IA and PG and the substrates for sulfotransferase (SULT) are DNF, AL, PG and BPG.

\section{Toxicological study}

Table 5 shows the results of mutagenic (Ames test) and carcinogenic (using mouse and rat model) properties of DNF, AL, IA, AGD, BPG, PC and TC. Toxicological investigation of drug candidates is one of the key steps for drug discovery. This means that the toxicity study is very important for new compounds.

The Ames test is widely used and accepted test to evaluate the mutagenicity of a chemical agent. In this test, different strains of Salmonella typhimurium bacterium with mutations in genes involved in histidine synthesis were used and the test compound is considered to be mutagenic if it enables the mutated bacterium to grow histidine-exempt medium i.e. if it stimulates the reversion process (Mortelmans and Zeiger, 2000). In this in silico mutagenicity investigations all the compounds except TC exhibited positive prediction i.e. mutagenic compound.

In carcinogenicity study, the PreADMET server was utilized to predict the carcinogenicity of chemical agent. The data generated from the in vivo carcinogenicity tests for mice and rats for 2 years of the National Toxicology Program (NTP) and the USA/FDA are used to build this server.

In the prediction of carcinogenicity negative prediction indicates there is evidence of carcinogenic activity whereas positive means the tested compound does not exhibit carcinogenic activity. Among all the natural anti-tubercular agents only DNF and TC demonstrated carcinogenicity in both mouse and rat model. The AL and PG were carcinogenic only in mouse but in rat model they showed positive prediction. On the other hand, IA, BPG and PC were non carcinogenic in both mouse and rat model. The risk of inhibition of human ether-a-go-go-related (hERG) gene was varied from low to medium. Inhibition of the hERG gene has been linked to long QT syndrome (Sanguinetti et al., 2006). The results have been in summarized in Table 5 .

\section{CONCLUSION}

The calculated physicochemical properties demonstrates that all the screened compounds are lipophilic in nature and obeyed Lipinski's rule of 5 (Lipinski et al., 2001) except 
tiliacorine (TC) which has partition coefficient value above 5 $(\log \mathrm{P})$. This lipophilicity explains why these compounds possess high human intestinal absorption (HIA), Caco-2 cell permeability and ability to cross BBB i.e. likeliness to be $\mathrm{CNS}$ active. Further, among all the compounds the BPG and TC demonstrated dual activity against P-glycoprotein i.e. both can act as inhibitor and substrate of P-glycoprotein similar to Quinidine (Zhou, 2008). On the other hand, virtual screening suggests that IA is a Pgp inhibitor and hence, co-administration of IA with drugs which are Pgp substrate would be therapeutically advantageous (Zhou, 2008). The prediction of metabolic characteristic displayed that DNF, AL, IA, PC and TC are substrates for cytochrome P450 3A4 and in phase II reaction, IA, PG and DNF, AL, PG, BPG are the substrates for UGT and SULT, respectively. The toxicological investigation showed that all the compounds except TC are mutagenic. However, a mutagenic compound may not be a carcinogen which is supported by the carcinogenicity investigation where IA, BPG and PC were non carcinogenic in both mouse and rat models.

\section{Financial support and sponsorship: Nil.}

Conflict of Interests: The authors' declare no conflict of interest.

\section{REFERENCES}

Abdallah EM. Plants: An alternative source for antimicrobials. Journal of Applied Pharmaceutilcal Science, 2011; 1: 16-20.

Adegboye M, Babalola O. Actinomycetes: A Yet Inexhaustive Source of Bioactive Secondary Metabolites. In: Mendez-Vilas, A., Ed., Microbial Pathogens and Strategies for Combating Them: Science, Technology and Education, Formatex, Badajoz, 2013; 786-795.

Aly AH, Debbab A, Proksch P. Fifty years of drug discovery from fungi. Fungal Diversity, 2011; 50: 3-19.

Cabrera MA, Gonzalez I, Fernandez C, Navarro C, Bermejo M. A topological substructural approach for the prediction of P-glycoprotein substrates. J Pharm Sci. 2006; 95: 589-606.

Cunha EL, Santos CF, Braga FS, Costa JS, Silva RC, Favacho HA, Hage-Melim LI, Carvalho JC, da Silva CH, Santos CB. Computational Investigation of antifungal compounds using molecular modeling and prediction of ADME/Tox properties. Journal of Computational and Theoretical Nanoscience. 2015; 12: 3682-91.

de Cerqueira Lima P, Golbraikh A, Oloff S, Xiao Y, Tropsha A. Combinatorial QSAR modeling of P-glycoprotein substrates. J Chem Inf Model. 2006; 46: 1245-54.

Joung JY, Kim H, Kim HM, Ahn SK, Nam K, No KT. Prediction Models of P-Glycoprotein Substrates Using Simple 2D and 3D Descriptors by a Recursive Partitioning Approach. Bull Korean Chem Soc. 2012; 33: 1123 1127.

Katiyar C, Gupta A, Kanjilal S, Katiyar S. Drug discovery from plant sources: An integrated approach. Ayu, 2012; 33: 10-19.

Kim RB, Fromm MF, Wandel C, Leake B, Wood AJ, Roden DM, Wilkinson GR. The drug transporter P-glycoprotein limits oral absorption and brain entry of HIV-1 protease inhibitors. J Clin Invest. 1998; 101: 289-94.

Kumar P, Singh A, Sharma U, Singh D, Dobhal MP, Singh S. Antimycobacterial activity of plumericin and isoplumericin against MDR Mycobacterium tuberculosis. Pulmonary Pharmacology \& Therapeutics, 2013; 26: 332-335.

Lipinski CA, Lombardo F, Doming BV, Feenay PJ. Experimental and computational approaches to estimate solubility and permeability in drug discovery and development settings. Adv. Drug. Deliv. Rev. 2001; 46: 3-26.
Luckner, S.R., Liu, N., Am Ende, C.W., Tonge, P.J., and Kisker C. Crystal structure of M. tuberculosis InhA inhibited by PT70. J. Biol. Chem. 2010; 285: 14330.

Mahajan GB, Balachandran L. Antibacterial agents from actinomycetes- A review. Frontiers in Bioscience (Elite Edition), 2011; 4: 240253.

Marvin 15.06.29, 2015, ChemAxon (http://www.chemaxon.com).

Mortelmans K, Zeiger E. The Ames Salmonella/microsome mutagenicity assay. Mutat. Res. 2000; 455 (1-2); 29-60.

Pandit R, Singh PK, Kumar V. Natural remedies against multi-drug resistant Mycobacterium tuberculosis. Journal of Tuberculosis Research, 2015; 3: $171-183$.

Patel JD, Parmar M, Patel P, Rohit P, Taviyad R, Ansari P, Bhattacharya B, Vyas D, Kumar V, Sahay NS, Singh PK. Dynamism of antimicrobial activity of actinomycetes- A case study from undisturbed microbial niche. Advances in Microbiology, 2014; 4: 324-334.

Prabu A, Hassan S, Prabuseenivasan Shainaba PAS, Hanna LE, Kumar V. Andrographolide: A potent antituberculosis compound that targets aminoglycoside 2'-N-acetyltransferase in Mycobacterium tuberculosis. Journal of Molecular Graphics \& Modelling, 2015; 61: 133-140.

Sanguinetti MC, Tristani-Firouzi M. hERG potassium channels and cardiac arrhythmia. Nature 2006; 440: 463-469.

Schinkel AH. P-glycoprotein, a gatekeeper in the blood-brain barrier. Adv Drug Deliv Rev. 1999; 36(2-3): 179-194.

Singh RK, Tiwari SP, Rai AK, Mohapatra TM. (2011) Cyanobacteria: An Emerging Source for Drug Discovery. The Journal of Antibiotics, 2011; 64: 401-412.

Sinko PJ (Ed). Martin's physical pharmacy and pharmaceutical sciences. $6^{\text {th }}$ Edition, Lippincott, 2010, 183.

Smith D, Ryan M. Fungal Sources for new drug discovery. Access Science, () McGraw-Hill Companies, 2009.

Sureram S, Senadeera SP, Hongmanee P, Mahidol C, Ruchirawat S, Kittakoop P. Antimycobacterial activity of bisbenzylisoquinoline alkaloids from Tiliacora triandra against multidrug-resistant isolates of Mycobacterium tuberculosis. Bioorganic \& Medicinal Chemistry Letters, 2012; 22: 2902-2905.

Tiwari N, Thakur J, Saikia D, Gupta MM. Antitubercular diterpenoids from Vitex trifolia. Phytomedicine, 2013; 20: 605-610.

Uc-Cachon AH, Borges-Argaez R, Said-Fernandez S, VargasVillarreal J, Gonzalez-Salazar F, Méndez-González M, Cáceres-Farfán M, Molina-Salinas GM. Naphthoquinones isolated from Diospyros anisandra exhibit potent activity against pan-resistant first-line drugs Mycobacterium tuberculosis strains. Pulmonary Pharmacology and Therapeutics, 2014; 27: 114-120.

Wang YH, Li Y, Yang SL, Yang L. Classification of substrates and inhibitors of P-glycoprotein using unsupervised machine learning approach. J Chem Inf Model. 2005;45:750-757.

Xiao-lei M, Cheng C, Jie Y. Predictive model of blood-brain barrier penetration of organic compounds. Acta Pharm Sinic. 2005; 26: 500-512.

Yee S. In vitro permeability across Caco-2 cells (colonic) can predict in vivo (small intestinal) absorption in man-fact or myth. Pharm. Res. 1997; 14: 763-766.

Yazdanian M, Glynn SL, Wright JL, Hawi A. Correlating partitioning and caco-2 cell permeability of structurally diverse small molecular weight compounds. Pharm. Res. 1998; 15: 1490-1494.

Zhou S. Drugs behave as substrates, inhibitors and inducers of human cytochrome P450 3A4. Current Drug Metabolism, 2008; 9: 310-322.

\section{How to cite this article:}

Khan MF, Bari MA, Islam MK, Islam MS, Kayser MS, Nahar N, Al-Faruk M, Rashid MA. The natural anti-tubercular agents: In silico study of physicochemical, pharmacokinetic and toxicological properties. J App Pharm Sci, 2017; 7 (05): 034-038. 